\title{
To study the outcome of previous one cesarean pregnancies in a rural tertiary center of Haryana, India
}

\author{
Siwach S., Lakra P.*, Sangwan V., Shivani, Kansal R., Mahendru R.
}

Department of Obstetrics and Gynecology, BPS, GMC, Khanpurkalan, Sonipat, Haryana, India

Received: 24 August 2017

Accepted: 25 September 2017

\section{*Correspondence:}

Dr. Lakra P.,

E-mail: drpinki_18@yahoo.com

Copyright: ( ) the author(s), publisher and licensee Medip Academy. This is an open-access article distributed under the terms of the Creative Commons Attribution Non-Commercial License, which permits unrestricted non-commercial use, distribution, and reproduction in any medium, provided the original work is properly cited.

\begin{abstract}
Background: Rising rates of caesarean section is a matter of great concern and TOLAC is an attractive alternative. Analysing outcome of previous one caesarean pregnancies will provide an insight for reducing the caesarean rates and formulating protocols and policies for TOLAC.

Methods: A retrospective study of patients of previous one caesarean pregnancy was done from February 2015 to January 2016 and 3 groups were made, ERCS group, failed TOLAC group and successful TOLAC group. The rates of elective repeat caesarean, failed TOLAC, successful TOLAC, maternal complications, neonatal morbidity and mortality in all three groups were studied.

Results: There were 5177 total deliveries with 488 (9.43\%) previous one caesarean pregnancies. Out of 488 patients $161(33 \%)$ underwent elective repeat caesarean and $327(67 \%)$ underwent trial of labour. Out of 327 patients 234 $(71.56 \%)$ had a successful TOLAC and $93(28.44 \%)$ had failed TOLAC. Breech (23\%) followed by foetal distress $(20 \%)$ were the most common indications of previous caesarean. Commonest indication of elective repeat caesarean was short interval (33\%) and that of failed TOLAC was foetal distress (38.7\%) followed by failed induction (23.6\%). There were 4 morbidly adherent placentas $(0.82 \%)$, 1 scar rupture, 3 scar dehiscence, no maternal mortality and 10 neonatal deaths.

Conclusions: Previous one caesarean section is not only a risk factor for repeat caesareans and complications like morbidly adherent placenta, uterine rupture but also a financial burden on health facilities. Encouraging the patients for trial of labour and emphasizing the usage of contraception is the need of the hour.
\end{abstract}

Keywords: Previous cesarean, TOLAC, VBAC

\section{INTRODUCTION}

The $20^{\text {th }}$ century witnessed a boom in caesarean rates from $5 \%$ (1970) to $25 \%$ (1988) and it is still continuing to rise with $31 \%$ in $2007 .^{1,2}$ The dictum 'once a caesarean always a caesarean' was followed by the concept of TOLAC with TOLAC rates as good as 40-50\% in 1996 but it reduced to only $8.5 \%$ by 2006 , because of the reports of rupture uterus and more strict guidelines by ACOG. ${ }^{1,2}$ TOLAC is a good alternative to a repeat caesarean section to avoid future complication associated with multiple caesareans like morbidly adherent placenta, surgical difficulties, injuries to adjacent viscera, multiple blood transfusions etc. But this too is not $100 \%$ safe. Maternal mortality after a rupture uterus in this era is very low but main insult is to the foetus with high morbidity and mortality. On the other hand, multiple caesareans not only increase maternal morbidity but also burden health system with extra cost. In India the present caesarean section rates are quite variable ranging from $6.2 \%$ (Bihar) to unacceptably high of $58 \%$ (Telangana) according to the $4^{\text {th }}$ NFHS $2015-2016 .{ }^{3}$ On analysing the 
recent caesarean delivery rates of western countries, it was found that Cesarean delivery rate in England for 2012-2013 was $25.5 \%$ and in United States for 2015 was $32 \% .4$ A high primary caesarean rate ultimately increases the incidence of previous one caesarean pregnancies and related complications. Since there have been changes in the trends of primary caesarean section rates and VBAC rates over decades, there is a need of audit from time to time.

Caesarean section rates are higher in urban areas as compared to rural areas and higher in the private as compared to the public health facilities. Ours is a study of a rural tertiary centre catering the rural population of Haryana. Careful case selection and continuous intrapartum foetal and maternal monitoring can successfully reduce repeat caesareans.

\section{METHODS}

A Record based retrospective study was done over period of one year from February 2015 to January 2016. Case files of patients of previous one cesarean sections were reviewed and 3 groups were made.

- Group 1: elective repeat cesarean section (ERCS) due to recurrent indication or absolute indication

- Group 2: failed TOLAC and

- Group 3: successful TOLAC.

As per hospital protocol the patients underwent TOLAC with the inclusion criteria of informed and written consent for TOLAC, singleton pregnancy, cephalic presentation, $\mathrm{Hb} \geq 8 \mathrm{gm} \%$, interpregnancy interval more than 18 months and adequate pelvis. Exclusion criteria were previous one cesarean pregnancy with any complicating factors.

Patients with no other high-risk factor were allowed to go till 40 weeks and induction of labor was done at completed 40 weeks with dinoprostone gel. Patients with bishops score less than 3 were taken for elective repeat cesarean. Patients and the family members of the TOLAC groups were counseled regarding the benefits and the risks associated with the success and failure. Admission CTG was done for all patients and labour progress was monitored with a partograph and CTG.

Clinical signs of scar dehiscence and rupture with the vitals monitoring, vaginal bleeding, abnormal CTG and scar tenderness were looked for. The results were analyzed using Microsoft excel and SPSS 20 by calculating average, range, standard deviation and percentage. Chi square test, $t$ test and ANOVA were applied where ever required for comparisons among the groups.

\section{RESULTS}

There were 5177 total deliveries during the study period with 488 previous one caesarean pregnancies with the incidence of $9.43 \%$ of previous one caesarean patients coming to labour ward. Out of 488 patients 161 (33\%) underwent elective repeat caesarean and 327 (67\%) were taken for trial of labour as per hospital protocol. Out of 327 patients $234(71.56 \%)$ had a successful TOLAC and $93(28.44 \%)$ had a repeat caesarean section and hence failed TOLAC. The demographic profile is depicted in Table 1 . In all the groups most of the patients belonged to rural areas.

Table 1: Demographic profile.

\begin{tabular}{|lllll|}
\hline Demographic profile & ERCS group (161) & $\begin{array}{l}\text { Failed TOLAC } \\
\text { group (93) }\end{array}$ & Successful TOLAC (234) & P value \\
\hline Mean age in years $( \pm 2 S D)($ range) & $25.63( \pm 3.69)(20-36)$ & $25.15( \pm 2.02)(22-32)$ & $25.54( \pm 3.11)(20-40)$ & 0.474 \\
\hline Mean parity & 1.26 & 1.22 & 1.3 & 0.214 \\
\hline Mean period of gestation in weeks & 37.55 & 37.92 & 37.62 & 0.000 \\
\hline
\end{tabular}

Table 2: Indication of primary caesarean section.

\begin{tabular}{|c|c|c|c|c|}
\hline Indication of caesarean in last pregnancy & ERCS group & Failed TOLAC group & Successful TOLAC & Total \\
\hline Malpresentations (breech) & $40(36)$ & $16(14)$ & $73(62)$ & $129(112)$ \\
\hline Foetal distress & 27 & 27 & 44 & 98 \\
\hline NPOL & 20 & 18 & 46 & 84 \\
\hline Failed induction & 24 & 17 & 14 & 55 \\
\hline $\mathrm{APH}$ & 10 & 5 & 6 & 21 \\
\hline Preeclampsia/eclampsia & 11 & 3 & 10 & 24 \\
\hline Contracted pelvis & 10 & 0 & 0 & 10 \\
\hline CPD & 5 & 0 & 4 & 9 \\
\hline Cord complications & 3 & 0 & 5 & 8 \\
\hline Others & 11 & 7 & 32 & 50 \\
\hline Total & 161 & 93 & 234 & 488 \\
\hline
\end{tabular}


The average interpregnancy interval in ERCS group was $33.24 \pm 27.22$ months (range 11-204), in failed TOLAC group was $38.73 \pm 17.95$ months (range of 18-96) and in successful TOLAC group was $38.76 \pm 20.26$ months (range of 18-144) (p value 0.001). As shown in Table 2, malpresentation mainly breech $(26.4 \%)$ followed by fetal distress $(20 \%)$ happened to be the most common indications of previous cesarean. Table 3 depicts that the most common indication of elective repeat cesarean was short interval in $33 \%$ patients of ERCS group whereas in failed TOLAC group it was fetal distress $(38.7 \%)$ followed by failed induction $(23.6 \%)$ and scar tenderness $(22.5 \%)$.

Table 3: Indications of cesarean section in present pregnancy in ERCS and failed TOLAC group.

\begin{tabular}{lll}
\hline Indications & ERCS & Failed TOLAC \\
\hline Short interval & $53(33 \%)$ & - \\
\hline Malpresentation & $26(16.1 \%)$ & - \\
\hline Contracted pelvis & $17(10.5 \%)$ & - \\
\hline Refusal for TOLAC & $12(7.4 \%)$ & - \\
\hline Placenta previa & 10 & - \\
\hline Preeclampsia/eclampsia & 10 & - \\
\hline CPD & 11 & - \\
\hline Prom with poor bishops & 8 & - \\
\hline Foetal distress & - & $36(38.7 \%)(2$ \\
& & scar dehiscence $)$ \\
\hline Failed induction & - & $22(23.6 \%)$ \\
\hline Scar tenderness & - & $21(22.5 \%)(1$ \\
\hline DTA & - & scar dehiscence $)$ \\
\hline NPOL & - & 5 \\
\hline Scar rupture & - & 5 \\
\hline Others & 14 & 1 \\
\hline Total & 161 & 93 \\
\hline
\end{tabular}

It was observed that $73.7 \%$ of primary cesareans were done in health facilities other than tertiary hospitals. Contraceptive usage was there in only $12.9 \%$ patients as a whole. Table 4 shows maternal complications in all three groups. There were 4 morbidly adherent placentas $(0.82 \%)$ out of 488 previous one cesarean pregnancies, 3 of them underwent cesarean hysterectomies and one was managed with conservative surgery. The incidence of scar rupture was $0.3 \%$ and that of scar dehiscence $0.9 \%$.

In the failed TOLAC group 3 patients had scar dehiscence ( 2 patients of the fetal distress and 1 patient of scar tenderness) and 1 had scar rupture. There was no morbidity or mortality in neonates of scar dehiscence but the neonate of scar rupture was still born. The bladder tear and uterus of uterine rupture case were repaired successfully. Other complications like wound sepsis and pyrexia were more common in Failed TOLAC group as compared to Successful TOLAC group. There was no maternal mortality. The ERCS and Failed TOLAC group patients had more blood transfusions as compared to the
Successful TOLAC group patients 55/254 versus 14/234 ( $p$ value 0.00 ). The average hospital stay in ERCS group was $7.2 \pm 5.18$ days (range $3-45$ days), in failed TOLAC group 7.5 \pm 4.67 days (range 3-30 days) whereas in successful TOLAC group it was $2.23 \pm 1.48$ days (range 15 days). $P$ value was 0.00 highly significant when successful TOLAC group is compared with both cesarean groups.

Table 4: Complications in present pregnancy.

\begin{tabular}{|c|c|c|}
\hline Complications (n) & $\begin{array}{l}\text { ERCS } \\
\text { (161) }\end{array}$ & $\begin{array}{l}\text { Failed TOLAC + } \\
\text { successful } \\
\text { TOLAC }(93+234)\end{array}$ \\
\hline Severe anaemia & 22 & $15+11$ \\
\hline \multirow{3}{*}{ Preeclampsia } & 25 & $18+23$ \\
\hline & Mild - 5 & \\
\hline & Severe - 20 & \\
\hline Placenta previa & 10 & $0+0$ \\
\hline $\begin{array}{l}\text { Morbidly adherent } \\
\text { placenta }\end{array}$ & 4 & $0+0$ \\
\hline \multicolumn{3}{|l|}{$\begin{array}{l}\text { Intraoperative } \\
\text { complications }\end{array}$} \\
\hline Dense adhesions & 30 & $13+0$ \\
\hline Bladder injury & 1 & $1+0$ \\
\hline Thin scar & 8 & $8+0$ \\
\hline Scar dehiscence & 0 & $2+0$ \\
\hline Scar rupture & 0 & $1+0$ \\
\hline $\begin{array}{l}\text { Morbidly adherent } \\
\text { placenta }\end{array}$ & 4 & $0+0$ \\
\hline $\begin{array}{l}\text { Caesarean } \\
\text { hysterectomy }\end{array}$ & 3 & $0+0$ \\
\hline \multicolumn{3}{|l|}{ Other complications } \\
\hline Blood transfusion & 40 & $15+14$ \\
\hline Traumatic PPH & 0 & $0+1$ \\
\hline Atonic PPH & 4 & $2+2$ \\
\hline Pyrexia & 4 & $3+1$ \\
\hline Wound sepsis & 6 & $5+1$ \\
\hline Paralytic ileus & 3 & $4+0$ \\
\hline $\begin{array}{l}\text { Extended hospital } \\
\text { stay }>2 \text { days }\end{array}$ & 161 & $93+53$ \\
\hline
\end{tabular}

Table 5: Neonatal outcome.

\begin{tabular}{|lllc|}
\hline $\begin{array}{l}\text { Neonatal } \\
\text { outcome (n) }\end{array}$ & $\begin{array}{l}\text { ERCS } \\
(161)\end{array}$ & $\begin{array}{l}\text { TOLAC } \\
\text { group (327) }\end{array}$ & P value \\
$\begin{array}{l}\text { Weight in kg } \\
\text { (mean) }\end{array}$ & 2.81 & 2.63 & 0.10 \\
\hline $\begin{array}{l}\text { NICU } \\
\text { admissions }\end{array}$ & $17(10.5 \%)$ & $31(9.5 \%)$ & 0.74 \\
\hline Mortality & $3(1.8 \%)$ & $7(2.1 \%)$ & 0.83 \\
\hline FSB & 0 & $\begin{array}{l}1 \text { (rupture } \\
\text { uterus) }\end{array}$ & \\
\hline
\end{tabular}

Table 5 shows neonatal outcome. There were $10.5 \%$ NICU admissions in ERCS group as compared to $9.5 \%$ in TOLAC group. There were three neonatal mortalities in ERCS group ( 2 preterm with sepsis and 1 was severe 
1UGR with sepsis) and three in failed TOLAC group (1 rupture uterus, 1 TOF, 1 hyperbilirubinemia). In Successful TOLAC group there were four neonatal mortalities, three newborns were extremely preterm and one developed sepsis. There were 10 IUFD 9 of which were taken for TOLAC and all of them delivered vaginally. One out of the 10 IUFD was preterm transverse lie with cord prolapsed and underwent ERCS.

\section{DISCUSSION}

There has been a continuous rise in the cesarean rates and a 2011 study calculates that if trends continue, the 2020 cesarean rate will be $56.2 \%$ which is alarming high. ${ }^{6}$ With the upcoming studies and metanalysis on TOLAC it has become a good option for reducing the incidence of repeat cesarean deliveries.

The overall TOLAC rates in US studies are $58 \%$ whereas in our study it was $67 \% .^{7}$ In an Indian study it was noted that $43.1 \%$ of the patients of previous one cesarean pregnancies eligible for TOLAC refused for it in contrast to $3.5 \%$ of our patients and opted for elective repeat cesarean which means there is a need for repeated counseling which should begin right in the early antenatal period as specially emphasized by RCOG. ${ }^{8}$

Doshi et al depicted in his study that patients with prior LSCS for malpresentations had $42 \%$ successful VBAC and in the present study it was $50 \%$. Hence TOLAC should always be offered to such patients. ${ }^{9}$ Mishra et al in their study have depicted that the most common indication of previous cesarean was breech followed by non-progress of labour, this is in accordance to the present study. ${ }^{10}$ Present study found that $23 \%$ of patients in all three groups had breech as indication of previous cesarean, which could have been reduced to some extent at least, by doing an assisted vaginal breech delivery. Hence by practicing assisted vaginal breech delivery and external cephalic version in selective cases we can certainly reduce the incidence of previous one cesarean pregnancy.

In a study by Bangal et al and Shah et al the most common indication of failed TOLAC was fetal distress which is similar to our results. ${ }^{11}$ A literature review suggests that there is $60-80 \%$ success in TOLAC. ${ }^{12}$ The successful TOLAC rate in the present study is $71.56 \%$ and is comparable to other studies. The successful TOLAC rates in Indian studies are much better than the developed countries like USA (13.8\%) and Australia $(43 \%) .^{13,14}$

The incidence of scar rupture in the present study was $0.3 \%$ and the ACOG estimates it to be 0.2 to $1.5 \%{ }^{1}$ Shipp et al studied the risk of scar dehiscence in relation to the interval between a previous CS and the present pregnancy and found that the rate of scar rupture was $2.3 \%$, when the interval was less than 18 months as compared to $1 \%$, when the interval was more than 18 months. ${ }^{15}$ The lower incidence of scar rupture in the present study was because as per hospital protocol only patients with interval more than 18 months were taken for TOLAC and strict fetomaternal monitoring of patients in labour was done. The maternal morbidity in terms of intraoperative and postoperative complications, blood transfusion, and extended hospital stay was more in the ERCS and failed TOLAC group as compared to successful TOLAC group. The fetal morbidity in ERCS in terms of NICU admission was seen in $10.5 \%$ neonates as compared to $9.5 \%$ in TOLAC group ( $p$ value 0.74 ). McMohan et al in a study on comparison of trial of labour with elective second cesarean, stated that there were similar rates of NICU admissions and prenatal mortality in both the groups. ${ }^{16}$ Most of the cases of NICU admission in successful TOLAC group were due to low birth weight and prematurity and in other two groups were because of respiratory distress and meconium aspiration. There were 3 neonatal mortalities in ERCS group and failed TOLAC group each and 4 in successful TOLAC group and prematurity and sepsis were the main causes (p value 0.83).) Chhabra et al also quoted a zeromaternal mortality rate and a morbidity rate of $0.68 \%$, which was unrelated to trial of labor. ${ }^{17}$ Women considering planned VBAC should be informed that this decision carries a 2-3/10,000 additional risk of such birth related perinatal death when compared with ERCS. The women should be told that the absolute risk of TOLAC related perinatal loss is comparable to the risk for women having their first birth. ${ }^{9}$ A review of literature suggests that ERCS does not affect any decrease in fetal or maternal mortality and instead further increases costs borne out of increased hospital stay and maternal morbidity. ${ }^{18,19}$

Short interval has been the most common indication of ERCS as in $33 \%$ of the patients which could be reduced by a good contraceptive counseling beginning in the antenatal period itself, as only $11.2 \%$ of ERCS group and $12.9 \%$ of all the groups patients had used contraceptives. In the present study the analysis showed that $73.7 \%$ of first cesareans were done in health facilities other than tertiary hospitals where continuous electronic fetal monitors and adequate staff is generally not available and also for the fear of medico legal liabilities.

The need of the hour is not only the reduction in primary cesareans but also the repeat cesareans and TOLAC is a reasonably good option. The various societies like RCOG, ACOG, RANZCOG have emphasized on the proper antenatal counseling of the women explaining the risks and benefits and planning of the place of delivery which should be no less than a well-equipped hospital with 24 hours cesarean facilities and blood bank.

Case selection for TOLAC should be done by a senior obstetrician and a scoring system with predictors of successful outcome like spontaneous onset of labour, previous history of vaginal delivery, estimated birth weight less than $3 \mathrm{~kg}$, non-recurrent indication of 
previous cesarean, interpregnancy interval less than 18 months etc can be developed for supporting the decision for mode of delivery. By achieving a successful TOLAC the financial burden on the health care provider and family is substantially reduced and also is the incidence of previous 2 cesarean pregnancies. Early maternal recovery, reduction in need for blood transfusion, anesthetic complications, surgery related complications like injuries to bladder and bowel, fever, wound sepsis, urinary tract infections, morbidly adherent placenta and its related comorbidities are other advantages. But the risk of uterine rupture and neonatal mortality in even a single case out of thousands is enough to put down the morale of the Obstetrician. Similarly, a single case of morbidly adherent placenta can turn into a nightmare which sometimes might even cost the patient's life. Careful case selection, antenatal counseling for TOLAC by consultant obstetrician and strict monitoring of labour of TOLAC cases are the keys to a successful outcome of a previous cesarean pregnancy.

\section{CONCLUSION}

Previous one caesarean section is not only a risk factor for repeat caesareans and complications like morbidly adherent placenta, uterine rupture but also a financial burden on health facilities. Encouraging the patients for trial of labour and emphasizing the usage of contraception is the need of the hour.

\section{Funding: No funding sources}

Conflict of interest: None declared

Ethical approval: The study was approved by the Institutional Ethics Committee

\section{REFERENCES}

1. American College of Obstetricians and Gynecologists. ACOG Practice Bulletin No. 54: vaginal birth after previous cesarean. Obstet Gynecol. 2004;104:203-12.

2. American College of Obstetricians and Gynecologists. ACOG Practice Bulletin No. 115: vaginal birth after cesarean delivery. Obstet Gynecol. 2010;116:450-63.

3. Key indicators for India from NFHS 2015-2016. Available at http://www.nfhsindia.org/factsheet.html Accessed on 10 July, 2017.

4. Health and social care information center. NHS Maternity Statistics - England, April 2012 to March 2013: Provider level analysis. [Leeds]: HSCIC. 2013. Available at http://www.hscic. gov.uk/catalogue/PUB12744 Accessed 2015 Mar 18.

5. Martin JA, Hamilton BE, Osterman MJK. Births: Final data for 2015 national vital statistics report; Hyattsville, MD: National Center for Health Statistics. 2017;66(1).

6. Deline J, Varnes-Epstein L, Dresang LT, Gideonsen M, Lynch L, Frey JJ. Low primary cesarean rate and high
VBAC rate with good outcomes in an Amish birthing centre. Ann Fam med. 2012;10(6):530-7.

7. Guise JM, Eden K, Emeis C, Marshall N, Walker M, Fu $\mathrm{R}$, et al. Vaginal birth after cesarean: new insights. Evidence Report/Technology Assessment No. 191 (Prepared by the Oregon Health \& Science University Evidence-based Practice Center under contract no. 2902008-10057-I). AHRQ Publication No. 10-E003. Rockville (MD): Agency for Healthcare Research and Quality; 2010.

8. Jinturkar AA, Dongaonkar D. Study of obstetric and fetal outcome of post cesarean section pregnancy at tertiary care centre. Int $\mathbf{J}$ Recent Trends Sci Tech. 2014;10(3):530-7.

9. Doshi HU, Jain RK, Vazirani AA. Prognostic factors for successful vaginal birth after cesarean section analysis of 162 cases. J Obstet Gynecol Ind. 2010;60(6):498-502.

10. Mishra N, Taori N, Misri A. Fetomaternal outcome of pregnancy with previous cesarean section. J Evolution Med and Dent Sci. 2014;3(47):11369-78.

11. Bangal VB, Giri PA, Shinde KK, Gavhane SP. Vaginal birth after cesarean. North Am J Med Sci. 2013;5(2):140-4.

12. Shah JM, Mehta MM. Analysis of mode of delivery in women with previous one cesarean section. J Obstet Gynecol India. 2007;59(2):136-9.

13. Crowther CA, Dodd JM, Hiller JE, Haslam RR, Robinson JS. Planned vaginal birth or elective repeat caesarean: patient preference restricted cohort with nested randomised trial. PLoS Med. 2012;9(3):e1001192.

14. Wise MR, Anderson NH, Sadler L. Ethnic disparities in repeat caesarean rates at Auckland Hospital. Aust N Z J Obstet Gynaecol. 2013;53(5):443-50.

15. Shipp TD, Zelop CM, Repke JT, Cohen A, Lieberman E. Inter delivery interval and risk of symptomatic uterine rupture. Obstet Gynecol. 2001;97:175-80.

16. MacMohan MJ, Luther ER, Bowes WA, Olshan AF. Comparison of trial of labour with elective second cesarean. N Engl J Med. 1996;335:689-95.

17. Chhabra S, Arora G. Delivery in women with previous cesarean section. J Obstet Gynecol India. 2006;56:3047.

18. Shy L, Logerfo J, Karp L. Evaluation of elective repeat caesarean section as a standard of care. Am J Obstet Gynecol. 1981;139:123.

19. Royal college of obstetricians and gynecologists. Green top guideline No. 45. Birth after previous caesarean birth. 2007:1-31.

Cite this article as: Siwach S, Lakra P, Sangwan V, Shivani, Kansal R, Mahendru R. To study the outcome of previous one caesarean pregnancies in a rural tertiary center of Haryana, India. Int J Reprod Contracept Obstet Gynecol 2017;6:5008-12. 